\title{
Cold-blooded loneliness: Social exclusion leads to lower skin temperatures
}

\author{
Hans IJzerman ${ }^{\text {a, b,* }}$, Marcello Gallucci ${ }^{c}$, Wim T.J.L. Pouw ${ }^{\text {b }}$, Sophia C. Weißgerber ${ }^{\text {b }}$, \\ Niels J. Van Doesum ${ }^{\text {b }}$, Kipling D. Williams ${ }^{\mathrm{d}}$ \\ a Tilburg University, The Netherlands \\ ${ }^{\mathrm{b}}$ VU University, The Netherlands \\ c University of Milano-Bicocca, Italy \\ d Purdue University, United States
}

\section{A R T I C L E I N F O}

\section{Article history:}

Received 24 November 2011

Received in revised form 30 April 2012

Accepted 2 May 2012

Available online 18 June 2012

\section{PsycINFO codes:}

2340

\section{Keywords:}

Grounded cognition

Physical warmth

Relationships

Conceptual metaphors

Embodiment

\begin{abstract}
A B S T R A C T
Being ostracized or excluded, even briefly and by strangers, is painful and threatens fundamental needs. Recent work by Zhong and Leonardelli (2008) found that excluded individuals perceive the room as cooler and that they desire warmer drinks. A perspective that many rely on in embodiment is the theoretical idea that people use metaphorical associations to understand social exclusion (see Landau, Meier, \& Keefer, 2010). We suggest that people feel colder because they are colder. The results strongly support the idea that more complex metaphorical understandings of social relations are scaffolded onto literal changes in bodily temperature: Being excluded in an online ball tossing game leads to lower finger temperatures (Study 1), while the negative affect typically experienced after such social exclusion is alleviated after holding a cup of warm tea (Study 2). The authors discuss further implications for the interaction between body and social relations specifically, and for basic and cognitive systems in general.
\end{abstract}

(c) 2012 Elsevier B.V. All rights reserved.

\section{Introduction}

In the realm of social relations, people often use metaphors such as "she is cold and aloof" or "she is a warm person." Temperature metaphors conveniently establish and explain what is meant, and often show a remarkable similarity in imagery across languages. In particular, people's "social temperature" is central to the perception of relationships. These ideas are reminiscent of Asch's (1946) early work, which proposed psychological warmth as being the central dimension in which people judge one another (see also Fiske, Cuddy, \& Glicke, 2007). But what may be the underlying cause for the strong metaphorical connections between warmth and social relations? In later work, Asch (1958) advanced the theory that the metaphor of warmth may be related to the real, physical experience of warmth.

Metaphors based on physical warmth describing one's social relations have thus been suggested to combine elements of very concrete experiences and more abstract conceptions of how people think of others, learned early in life. In the present report, we will go beyond such metaphorical perspectives of warmth by suggesting that temperature changes constitute the "fabric" of social relations, hinging on specific, basic, and possibly biologically evolved simulators. We

\footnotetext{
* Corresponding author at: Department of Social Psychology, School of Social \& Behavioral Sciences, Tilburg University, The Netherlands.

E-mail address: h.ijzerman@uvt.nl (H. IJzerman).
}

hypothesized and found that people literally decrease in skin temperature after social exclusion. In addition, we found that "fooling" the fingers, by briefly stimulating them with a cup of warm tea, eliminates the negative feelings typically experienced after social exclusion.

\section{Metaphorical perspectives on warmth and social relations}

The recent metaphor perspective in psychology, proposed by cognitive linguists Lakoff and Johnson (1999) and antedated by Asch (1958), suggested that people experience concrete source domains (e.g., physical warmth) jointly with abstract target concepts (e.g., affection), and as a result "conflate" the mapping of physical warmth and affection (see also Johnson, 1997). Recent social psychological investigations seem to support this learning process: The experience of subtle manipulations of physical warmth (as compared to coldness) leads to the perception of another as more sociable (central to the person characteristic of "warm") and to greater prosocial behavior of the participant (Williams \& Bargh, 2008).

In addition, subtle manipulations of physical warmth (as compared to coldness) lead to cognitions that form the basis for communal relations: people in physically warmer conditions use more verbs (indicative of social closeness; Semin \& Fiedler, 1988), are more focused on relationships in their environment, and construe themselves as having greater psychological overlap with the experimenter (IJzerman \& Semin, 2009). In other words, due to learning that physical warmth 
and affection go hand-in-hand, people seem to develop mental representations that include both abstract conceptions of affectionate feelings and the sensorimotor experience of physical warmth, such that when they are in a warm environment, they will interact as if they are psychologically closer to others.

Yet, Lakoff and Johnson (1999) proposed unidirectionality to be central to such conceptual metaphors. Indeed, experiencing affection almost always includes physical warmth (but not vice versa), integrating the sensorimotor experience of physical warmth into the mental representation of affection, but characteristics of the mental representations of affection do not become an integral part of the mental representation of warmth (cf. Landau, Keefer, \& Meier, 2011). Such a perspective was confirmed in a different domain by Casasanto and Boroditsky (2008), who showed the connection between time and space. Indeed, they find that people's experience of space affects their perception of time, but not vice versa.

However, in the domain of physical warmth and affection, the effect seems to be bi-directional: When people are socially excluded or primed (either physically or psychologically) with distance they perceive ambient temperature as lower (for our theoretical background, see also IJzerman \& Koole, 2011; also IJzerman \& Semin, 2010; Zhong \& Leonardelli, 2008). Previous work has suggested that conceptual metaphors may be learned linguistically (Boroditsky, 2000), or experientially (Casasanto, 2008), allowing for possibilities to map such effects bidirectionally through the integration of sensorimotor experiences into the abstract concept domain. In addition, recent reviews support the idea that many conceptual metaphors may be dynamic and flexible (Santiago, Román, \& Ouellet, 2011). However, do experiences related to social relations rest on conceptual metaphors, or, if not, what may then account for earlier findings linking physical warmth and affection?

\section{Evolved primitives for social relations}

We propose that central to answering this question is the functionality of physical warmth in social relations and that the body may constrain people's learning processes for social relations. One may trace back our approach to Bowlby (1969), who suggested that 1) people become equipped with basic perceptual inputs to comprehend their social environment, and that 2) close relationships serve security-provision and distress-alleviation regulatory functions. In addition, Harlow's (1958) classical work suggested that close, physical comfort may be a biologically evolved need. He showed that close comfort is necessary for healthy psychological functioning, as young rhesus monkeys displayed a greater preference for terry-clothed surrogate mothers as compared to a wire mother, while those raised with a wire mother had greater physiological and psychological problems. Harlow's (1958) findings resonate with and predated the Relational Models Theory, which summarized people's basic forms of interactions into four elementary ways (Fiske, 1991).

The most basic of these interaction types are communal sharing relationships, which are relationships prototypically implemented among close kin. Examples of communal sharing relationships are relationships between mother-infant, close romantic partners, and tight knit military units. In order to be able to identify how to interact with whom in what way, Thomsen and Carey (in press) suggested that people may rely on evolved primitives for elementary social relations (see also IJzerman \& Cohen, 2011; Williams \& Bargh, 2008). Some support for this idea seems to be derived from developmental work: Priming 18-month old children with touch in the background of a picture (versus no touch) significantly increases helping behavior from those infants later (Over \& Carpenter, 2009).

The proposition that some kind of structure is present on which young children map their knowledge of social relations, is further buttressed by findings that securely attached children become more generous in physically warm conditions (versus cold), whereas insecurely attached children lack this effect (q.v. IJzerman, Karremans, Thomsen, \& Schubert, in press; IJzerman \& Koole, 2011). In order to learn such relational structures, some kind of basic system needs to be in place in order to learn which kind of relation needs to learn in which way. In other words, a basic type of model seems to be present among infants to engage in a basic (finite) set of relations. Even though the child consistently encounters a bigger parent, it does not map relative size to understand its trusting relation with the security-providing caregiver. Thomsen and Carey (in press) therefore suggest that "humans have evolved an innate, finite set of conceptual primitives that specify relational models for communal sharing $[. .$.$] coupled with innate input-analyzers that automati-$ cally identify some instances [...] in the social world".

\section{Warmth as the 'fabric' of social relations}

Indeed, research has supported that people often rely on perceptual symbols to represent and retrieve information. Theories on perceptual symbol systems argue that people's neural architecture for imagery and perception is the same architecture for conceptual knowledge (Barsalou, 1999). In order to identify whom to rely on early in life, we suggest that people come equipped with "evolved simulators," onto which later knowledge on sociocognitive metaphors (such as "holding warm feelings" towards someone) are scaffolded (Mandler, 1992; Williams, Huang, \& Bargh, 2009).

But what kind of simulators may be relevant for social relations? Fransson, Karlsson, and Nilsson (2005) found provocative evidence that when a baby was held by the mother, the mean difference between core and skin temperature was much lower than when the baby was in its cot. Relatedly, loneliness leads to relatively high levels of total peripheral resistance, whereas people who are more socially connected have relatively high cardiac output and better levels of autonomic activity (Uchino, Cacioppo, \& Kiecolt-Glaser, 1996; for an overview see Cacioppo et al., 2002). A sense of disconnection may lead to vasoconstriction, a state in which the blood vessels are narrowed, maintaining body heat in the core, but not the periphery (like one's finger temperature). Such responses are probably built onto more basic human responses, work on which suggests that in times of threat (such as stress, fear or pain), skin temperature drops (Mittelmann \& Wolff, 1939). Empirical evidence since has supported this view (e.g., see Boudewyns, 1976; for an overview see Rimm-Kaufman \& Kagan, 1996).

Together, these findings suggest that skin temperature plays a vital role in interpersonal relations. In other words, when people are excluded from social interactions, they may literally get colder fingers. Adding to the idea of mental schemas, we suggest that concepts related to social relations rely on evolved simulators that may sense physical warmth. Concretely, when people engage in social interactions they should experience bodily temperature re-adjustments. In order to test this proposition, we used a well-validated interaction paradigm from social psychology, which has been used in over 70 studies (e.g., see Williams, Cheung, \& Choi, 2000; Williams, 2007; Van Beest \& Williams, 2006). ${ }^{1}$ Note that we hereby identify a simulator, and presuppose the possibility of an innate biologically evolved structure rather than empirically proving this proposition.

\section{Research overview}

In two studies, we aim to support the hypothesis that people experience literal temperature changes to process close and affiliative relations. In our first study, we expected that if participants were socially excluded, skin temperatures would drop. Conversely, in our second study, we expected that if we artificially stimulated the periphery of people's hands with physical warmth, people should perceive as if they were again socially connected, causing negative affect typically experienced after social exclusion to be alleviated.

\footnotetext{
${ }^{1}$ A list of these studies is available at http://www1.psych.purdue.edu/ willia55/ Announce/Cyberball_Articles.htm.
} 


\section{Study 1: social exclusion is cold}

\subsection{Method}

\subsubsection{Participants}

Forty-one VU University students (60.9\% female; $M_{\text {age }}=20.32$; $\left.S D_{\text {age }}=2.09\right)$ were alternatingly assigned to the inclusion $\left(n_{\text {net }}=20\right)$ or the exclusion condition $\left(n_{\text {net }}=21\right)$. One participant was excluded for technical failure during temperature measurement.

\subsubsection{Procedure and design}

In our first experiment, we ran individual sessions as part of an experiment supposedly on concentration. After entering the lab, participants first read and answered questions of a neutral text on the history of cognitive psychology and behaviorism (unrelated to the purpose of the present experiment), which served as our baseline measure. All participants had a fixed, pre-determined amount of time for the baseline measure. Participants then played a commonly-used ball-tossing paradigm, called "Cyberball" (Williams \& Jarvis, 2006; Williams et al., 2000). In Cyberball, the participant and two other ostensible human players toss around a ball in a computer-generated game. Participants played as a third player and received the ball every two throws (Inclusion Condition) or did not receive the ball from the "co-players" (Exclusion Condition) after the first two throws. Earlier studies have found that social separation from others even in a virtual ball-tossing game has severe detrimental affective consequences (Eisenberg, Lieberman, \& Williams, 2003). Finger temperature of participants' index fingers of the non-dominant hand was measured continuously through a device commonly used for industrial coolers, for a total of 24 times (with intervals of on average $15.6 \mathrm{~s}$, measured with $0.03125^{\circ} \mathrm{C}$ accuracy; see also Fig. 1).

\subsection{Results}

To control for individual variances in finger temperature, we obtained baseline temperatures during the reading of the text, with computed averages over 4.7 measurements (lasting for approximately $7 \mathrm{~s}$ each). Baseline temperatures were subtracted from each value obtained after the start of the experimental manipulation to obtain temperature variation scores. The resulting variables were analyzed with a growth-model obtained as a general mixed-model with time of measurement as a continuous independent variable with random effects and experimental manipulation (exclusion vs. inclusion) as dichotomous independent variables. Participants' average temperature and time effect were modeled as random. The degrees of freedom were computed based on a Kenward-Roger method (Kenward \& Roger, 1997). The trend of temperature over time was estimated with a linear and a quadratic component (Aiken \& West, 1991). The quadratic component was not statistically significant $(F(1,37.7)=1.89, p=0.176)$ and thus removed from the model. The interaction between time components and experimental condition was computed to estimate the effect of the manipulation on the trend of temperature over time.

The analyses showed that participants' temperature changed throughout the experiment, depending on whether they were included or excluded from their group, $F(1,38)=6.07, p=0.018$. Excluded participants showed a decrease in finger temperature during the experiment $(B=-0.011, t(38)=-2.51, p=0.016)$, whereas included participants showed no detectable change in finger temperature $(B=0.005, t(37.9)=1.01, p=0.316$; see also Fig. 2$)$. Temperature differences between values after the experimental manipulation and the baseline measurement were compared between the included and excluded condition. The difference increased over time: When the manipulation was introduced, the difference between included and excluded participants was $0.099^{\circ} \mathrm{C}, F(1,38)=0.54, p=0.468$; half-way during the experiment the difference was $0.405^{\circ} \mathrm{C}, F(1,38)=4.78, p=0.034$, with the excluded group showing a temperature colder than baseline

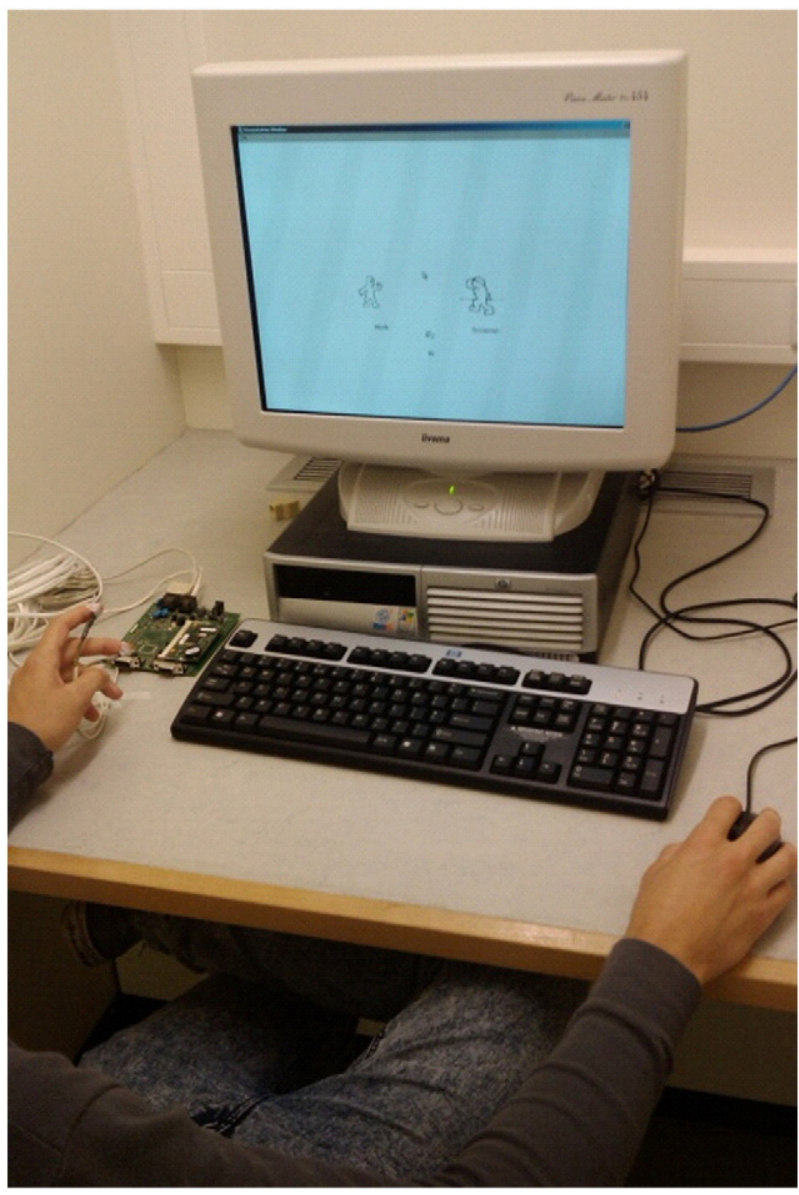

Fig. 1. Participant playing Cyberball, with measurement device connected to nondominant hand.

$\left(M_{\mathrm{ex}}=-0.163\right)$ and the included group warmer than baseline $\left(M_{\text {in }}=0.242\right)$; at the end of the experiment the difference was $0.711^{\circ} \mathrm{C}, F(1,38)=6.25, p=0.016$, with the inclusion group showing a slight, but non-significant, increase (as compared to baseline) $\left(M_{\mathrm{in}}=0.333\right)$, and the exclusion group a decrease of $0.378^{\circ} \mathrm{C}\left(M_{\mathrm{ex}}=\right.$

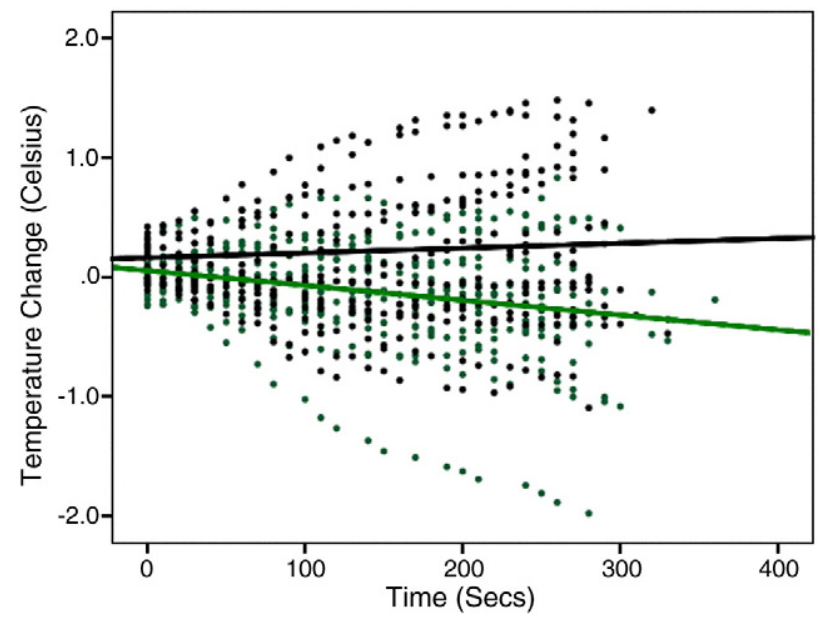

Fig. 2. Predicted change in temperature over time, for each participant (dots) and for the two groups (lines). Green dots indicate participants in the exclusion condition, black dots participants in the inclusion condition. The green line indicates average predicted values in the excluded condition, black line indicates averages for included condition. 
-0.378). Participants thus literally had colder skin temperatures after they were excluded from a group playing a ball-tossing game. ${ }^{2}$

\section{Study 2: how warmth rekindles the 'soul'}

Based on the results obtained in our first experiment, we hypothesized that people's skin temperature 'simulations' are important for people in determining - consciously or not - their affective state. If this is correct, then artificially inducing warm fingers might alleviate people's negative affective states resulting from social exclusion. Physical warmth may fool the conceptual system by creating a state as-if the relation was present (see Damasio, 1999; IJzerman \& Semin, 2009; Williams \& Bargh, 2008), paralleling a sensation of interpersonal touch. In line with Bowlby's (1969) ideas that 1) people become equipped with basic perceptual inputs to comprehend their social environment, and that 2) close relationships serve security-provision and distress-alleviation regulatory functions, we hypothesized that physical warmth repairs the relationship of those who are excluded. Our hypothesis is supported by recent findings that people use physical warmth nonconsciously as a self-regulatory mechanism to buffer against loneliness (Bargh \& Shalev, 2012).

In order to measure whether the conceptual system could indeed be fooled, we requested participants to report their affective states as a proxy instead of reporting directly about their experience of the induced relationship. In earlier research, IJzerman and Semin (2010) found that priming participants through language with their reported relationship state induces commensurable results to their real experience.We thus chose not to ask participants directly about their social experience, but instead about affective states, which have been reported to serve as a reliable proxy to measure feelings of exclusion (cf. Eisenberg et al., 2003; for a recent meta-analysis, see Gerber \& Wheeler, 2009). In our second study, we therefore expected that if participants would be induced with a subtle prime of physical warmth, their negative affect would disappear after social exclusion. We did not expect this effect to occur for the cold condition.

\subsection{Method}

\subsubsection{Participants}

Eighty-six VU University students (41.9\% female; $M_{\mathrm{age}}=20.55$; $S D_{\text {age }}=2.33$ ) took part in a computer-based study, again with a game of Cyberball. ${ }^{3}$

\subsubsection{Procedure and design}

In the second study we again excluded or included participants with the same ball-tossing paradigm. After exactly $3 \mathrm{~min}$ of playing, the game was interrupted by an ostensible (but preprogrammed) error screen, forcing participants to request help from our confederate. Our confederate entered the cubicle holding a glass mug containing either warm or cold tea and asked participants to temporarily (30 s) hold the glass, while fixing the 'error'. Our main dependent variable focused on the intensity of the average of four negative affective states which were used in earlier Cyberball research (Williams et al., 2000; Zadro, Williams, \& Richardson, 2004); all answered on a 5-point scale (bad,

\footnotetext{
${ }^{2}$ To test the robustness of our results against possible outliers, we used a jackknife methodology: We estimated the model after dropping one participant from the sample, repeating the estimation for each participant. Results showed that the crucial interaction (time $\times$ condition) remained significant in all jackknife samples, with $p$-values ranging from 0.008 to 0.035 . Thus, no particular participant was responsible for the effect we described in the entire sample. We also analyzed our data by excluding smokers from our sample, as they often experience greater difficulties in temperature regulation (Cleophas, Fennis, \& van't Laar, 1982). Our effects however remained virtually identical by excluding smokers, $F(1,28)=3.68, p=0.001$.

${ }^{3}$ Eleven participants were excluded from our analyses as they immediately put the glass of tea on the table, after receiving it from our confederate.
}

sad, tense, stressed, Cronbach's $\alpha=0.80$; e.g., "I felt bad"; from $1=$ not at all to $5=$ very $m u c h$ ). Participants were randomly assigned to one of four experimental conditions.

\subsection{Results}

Participants' reported negative affect served as dependent variable in a 2 (Cyberball: exclusion vs. inclusion) $\times 2$ (temperature: warm vs. cold) between-participants ANOVA.

The analyses showed that participants' reported negative affect depended on the combination of the inclusion manipulation and the temperature condition $\left(\eta_{\mathrm{p}}^{2}=0.071, F(3,82)=6.27, p=0.014\right)$. Excluded participants in the cold condition reported a greater level of negative affect as compared to the other three conditions $(F(1,82)=35.68$, $p<0.001$, and to the warm tea condition, $F(1,82)=11.22, p=0.001$. The exclusion-warm condition did not differ significantly from the two inclusion-conditions ( $F<1$; see also Fig. 3 ). Participants' negative feelings in the warm-exclusion condition were thus alleviated, confirming the idea that a warm cup can fool the conceptual system by reducing the negative effects of social exclusion.

\section{General discussion}

In our two experiments we found that people who were socially excluded showed a drop in finger temperature. Furthermore, warming the fingers through holding a warm cup of tea after a period of social exclusion alleviated negative affect typically experienced after social suffering. Our experiments are in line with the idea that perceptions of (physical) warmth play a central role in social cognition (Asch, 1946; IJzerman \& Semin, 2009; Semin \& Garrido, 2012; Semin \& Smith, 2008; Williams \& Bargh, 2008). Recent theoretical analyses have suggested that physical warmth is an inherent part of people's conceptual system, serving to understand social relations (Landau, Meier, \& Keefer, 2010). In the present research we go beyond these analyses by suggesting an additional interpretation. Physical warmth serves to repair the negative feelings of exclusion, and we suggest that people may use the perceptual system to interpret their social environment. We thus think that social exclusion leads to a decrease in skin temperature as an evolved simulator (Barsalou, 2008; IJzerman \& Koole, 2011).

There are a number of issues that need to be addressed. First, one may be concerned about the relation to earlier research, where specific emotions have been shown to map onto finger temperature. Ekman, Levenson, and Friesen (1983) for example found that people's finger temperature increases as a function of the expression of anger. A similar idea is reflected in research on the connection between abstract concepts and concrete experiences: People estimate temperature as

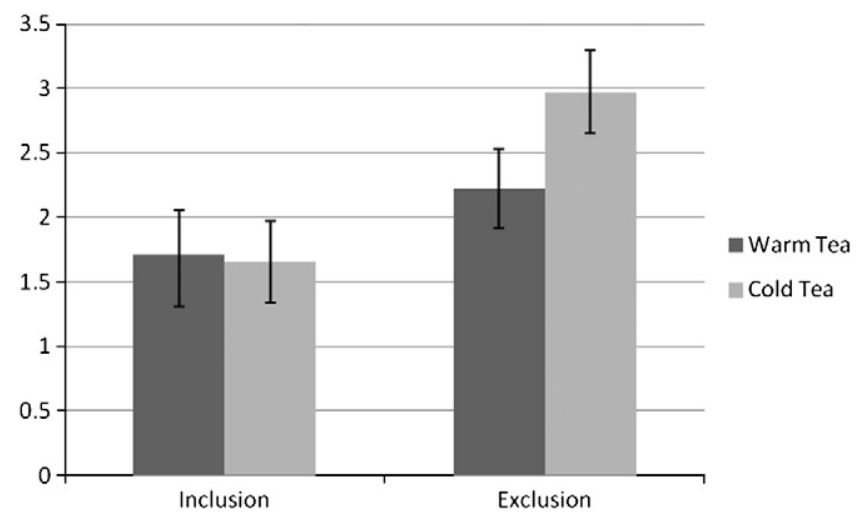

Fig. 3. Reported negative affect as a function of Cyberball condition and temperature condition. Error bars represent the standard error. 
higher when primed with anger (Wilkowski, Robinson, Meier, Carter, \& Feltman, 2009).

However, specific embodied states are not simple determinants of specific cognitions and/or behaviors like anger. When priming participants with psychological closeness (distance), they similarly estimate room temperatures to be higher (lower; IJzerman \& Semin, 2010). Comparable perceptual states may thus be associated with different affective or cognitive states, but may perhaps rely on slightly different multi-modal experiences (Barsalou, 2008). Importantly, the context of the situation and the complex internal representation of the person matters (cf. IJzerman \& Cohen, 2011). As such, it may be unclear how specific bodily states can be linked to specific types of emotions. In particular, sometimes the labeling of an emotion may even lead to different functionalities, leading us to wonder whether social and non-social anger relate in terms of their physiological profiles (cf. WilsonMendenhall, Barrett, Simmons, \& Barsalou, 2011).

Another important question is the meaning of physical warmth in relation to relationships. In the present work, we measured finger temperature to assess responses to exclusion and negative affect as a proxy of the state of participants' relationships. It was important to assess this indirectly, as we expected that to simply request participants to report about their broken relationship would induce an as-if state about the relationship, which research has suggested to a re-experience of the earlier physical "temperature simulation" (IJzerman \& Semin, 2010; see also Barsalou, 2008; Boroditsky \& Prinz, 2008; Damasio, 1999). Because we did not directly assess participants' phenomenological experience of the relationship, one may suggest that exclusion and physical warmth "simply" evoke hedonically charged cues.

We find this alternative account highly unlikely, for a number of reasons. First, across different reports, physical warmth does not make participants feel more positive (IJzerman \& Semin, 2009; Williams \& Bargh, 2008), which strongly points to the idea that physical warmth "repairs" the broken relationship, and only acquires hedonically charged meaning within a specific context (as also evidenced by the lack of decrease in negative affect in our inclusion condition). It thus seems that some kind of conceptual processing is necessary to trigger positive or negative affective states (see also Kavanagh, Andrade, \& May, 2005; Veltkamp, Aarts, \& Custers, 2008). This is further supported by findings showing affiliative and achievement needs to modulate affect in a Stroop paradigm (Kazén \& Kuhl, 2005). Bargh and Shalev's (2012) findings that people nonconsciously self-regulate their feelings of loneliness or disconnectedness through physical warmth further attest to our proposal. Finally, one may be reminded that our conception that sensing physical warmth has become part of an innate system converges with Harlow's (1958) classical findings, which suggest that close, physical comfort is an evolved need.

In addition, the means of the exclusion and inclusion conditions were nearly identical in terms of magnitude $\left(M_{i n c}=0.333\right.$ vs. $M_{\text {exc }}=$ -0.378 ), which seems to suggest a temperature increase in our inclusion condition. However, this change in our inclusion condition was non-significant. We think that this may be due to two potential causes. First, participants in the lab are not likely to be close and communal with relative strangers (whereas they might respond communally automatically to other close partners; see Häfner \& IJzerman, 2011). In addition, previous research finds that cues of psychological distance are more salient than cues of psychological closeness (IJzerman \& Semin, 2010), while feelings of inclusion in a ball-tossing game may not necessarily constitute an uplifting communal experience (Wesselmann, Bagg, \& Williams, 2009). We think that having participants interact either with close others or over-including them in the Cyberball game has the potential to show the proposed symmetry in temperature changes.

We do hasten to add that we do not mean that social exclusion does not cause a stress response. In fact, we believe that (very basic) stress responses are recycled for other (more complex) purposes. By recruiting such basic physiological processes, people early in life will be able to build reliable social relations, by knowing whom to rely on, and in what way. Indeed, people's more advanced cognitive system "re-uses" or is likely to be scaffolded onto more ancient neural systems (Anderson, 2010; Williams et al., 2009), in which stress responses form part of cognizing about social relations (Ganzel, Morris, \& Wethington, 2010).

\section{How social relations (may) 'work': future directions}

In terms of the representations of relationships, the link between physical warmth and affection has often been depicted as primarily constituted of top-down knowledge structures, conceptually linking image schemas of warmth and affection (Landau et al., 2010). We propose that such higher order representations are scaffolded onto actual biologically evolved simulators to mark, sustain, and sanction social relations (Fiske, 1991, 1992, 2004; Piaget \& Inhelder, 1969; Williams et al., 2009). This additional process is important also for broader issues concerning relationships, as it may lead to different research strategies in for example treatment of seasonal affective disorder (SAD), antisocial personality disorders, or client-patient relationships (see also Neumann et al., 2011).

We do think that higher order representations of relationship constitute a very important part of the way that people interact with one another. In particular, repeated social situations may become "entrenched," in that the situated conceptualization comes to differ from the originally evolved simulator (Barsalou, 1999, 2008; Schubert \& Koole, 2009), as in the case of internal working models of relationships (e.g., Johnson, Dweck, \& Chen, 2007). Internal working models of attachment modulate the way that young children respond to manipulations of physical warmth already early in life. In fact, IJzerman et al. (in press) found that young children who associate close relationships with safety and security (securely attached children) do become more generous in physically warm conditions, whereas those that lack this association also lack this effect (IJzerman \& Koole, 2011). In addition, differences in communality in a given relationship determine the level to which partners support each other automatically (Häfner \& IJzerman, 2011).

\section{Final remarks}

One of the universal aspects of human (social) psychology is to build and maintain relationships. Classic attachment theories assume that common building blocks of attachment are necessary in the first stages of life (Bowlby, 1969). For such elementary building blocks, evolved simulators may be indispensable. Our research suggests that physical warmth and social thinking are not just a function of the cultural (non)conscious structuring of experience. Rather than associations between colder temperatures and episodes of loneliness, we propose that evolved simulators are implemented across different generations, closely linking physical warmth and affection in the physical body (Caporael, 1997; Kaschak \& Maner, 2009; see also Harlow, 1958). Maternal touch seems to greatly impact the difference between core and skin temperature, preventing hypothermia, a major cause of death among neonates. In other words, the re-experience or perception of physical warmth might act as mechanism promoting initial survival in a social environment (cf. Kasahara, Takayanagi, Kawada, Itoi, \& Nishimori, 2007), which forms the basis for other mechanisms that are reliant on higher-order mental representations.

To close, we would like to note that the body's architecture is likely to have developed in order to be able to adapt and bond quickly, without conscious effort. We suggest that the understanding of abstract concepts like affection through concrete experiences such as physical warmth is often derived from specific affordances with which people have become equipped. People mark social relations through actual changes in bodily temperatures, possibly offering evolutionary advantages in early life stages. 


\section{Acknowledgments}

We are much indebted to Cor Stoof and the VU Helpdesk for their continued technical support and Sander Koole, Miguel Kazén, Julius Kuhl, Justin Saddlemyer, Alan Fiske's International Relational Models Lab, Larry Barsalou, the editor Michael Kaschak, and one anonymous reviewer for their inspiring discussions and/or helpful comments on an earlier version of this manuscript.

\section{References}

Aiken, L., \& West, S. G. (1991). Multiple regression: Testing and interpreting interactions. Newbury Park: Sage Publications.

Anderson, M. L. (2010). Neural reuse: A fundamental organizational principle of the brain. The Behavioral and Brain Sciences, 33, 245-313.

Asch, S. E. (1946). Forming impressions of personality. Journal of Abnormal Psychology, $41,258-290$.

Asch, S. E. (1958). The metaphor: A psychological inquiry. In R. Tagiuri, \& L. Petrullo (Eds.), Person perception and interpersonal behavior (pp. 86-94). Stanford: Stanford University Press.

Bargh, J. A., \& Shalev, I. (2012). The substitutability of physical and social warmth in daily life. Emotion, 1-32.

Barsalou, L. W. (1999). Perceptual symbol systems. The Behavioral and Brain Sciences, 22, 577-609.

Barsalou, L. W. (2008). Grounded cognition. Annual Review of Psychology, 59, 617-645.

Boroditsky, L. (2000). Metaphoric structuring: Understanding time through spatial metaphors. Cognition, 75, 1-28.

Boroditsky, L., \& Prinz, J. (2008). What thoughts are made of. In G. R. Semin, \& E. R. Smith (Eds.), Embodied grounding: Social, cognitive, affective, and neuroscientific approaches (pp. 98-115). New York: Cambridge University Press.

Boudewyns, P. A. (1976). A comparison of the effects of stress vs. relaxation instruction on the finger temperature response. Behavior Therapy, 7, 54-67.

Bowlby, J. (1969). Attachment and loss (first ed.). London: Hogarth Press.

Cacioppo, J. T., Hawkley, L. C., Crawford, L. E., Ernst, J. M., Burleson, M. H., Kowalewski, R. B., et al. (2002). Loneliness and health: Potential mechanisms. Psychosomatic Medicine, 64, 407-417.

Caporael, L. R. (1997). The evolution of truly social cognition: The core configurations model. Psychological Review, 1, 276-298.

Casasanto, D. (2008). Similarity and proximity: When does close in space mean close in mind? Mem Cognition, 36, 1047-1056.

Casasanto, D., \& Boroditsky, L. (2008). Time in the mind: Using space to think about time. Cognition, 106, 579-593.

Cleophas, T. J., Fennis, J. F., \& van't Laar, A. (1982). Finger temperature after a finger cooling test: Influence of air temperature and smoking. Journal of Applied Physiology, 52, 1167-1171.

Damasio, A. (1999). The feeling of what happens. London: Random House.

Eisenberg, N. I., Lieberman, M. D., \& Williams, K. D. (2003). Does rejection hurt? An fMRI study of social exclusion. Science, 302, 290-292.

Ekman, P., Levenson, R. W., \& Friesen, W. V. (1983). Autonomic nervous system activity distinguishes among emotions. Science, 221, 1208-1210.

Fiske, A. P. (1991). Structures of social life: The four elementary forms of human relations (first ed.). New York: Free Press.

Fiske, A. P. (1992). The four elementary forms of sociality: Framework for a unified theory of social relations. Psych. Rev., 99, 689-723.

Fiske, A. P. (2004). Relational models theory 2.0. In N. Haslam (Ed.), Relational models theory: A contemporary overview (pp. 3-25). London: Lawrence Erlbaum Publishers.

Fiske, S. T., Cuddy, A. J. C., \& Glicke, P. (2007). Universal dimensions of social cognition: Warmth and competence. Trends in Cognitive Sciences, 11, 77-83.

Fransson, A., Karlsson, H., \& Nilsson, K. (2005). Temperature variation in newborn babies: Importance of physical contact with the mother. Archives of Disease in Childhood. Fetal and Neonatal Edition, 90, 500-504.

Ganzel, B., Morris, P., \& Wethington, E. (2010). Allostasis and the human brain: Integrating models of stress from the social and life sciences. Psychological Review, $117,134-174$

Gerber, J., \& Wheeler, L. (2009). On being rejected: A meta-analysis of experimental research on rejection. Perspectives on Psychological Science, 4, 468-488.

Häfner, M., \& IJzerman, H. (2011). The face of love: Spontaneous accommodation as social emotion regulation. Personality and Social Psychology Bulletin, 1-13.

Harlow, H. F. (1958). The nature of love. American Psychologist, 13, 673-685.

IJzerman, H., \& Cohen, D. (2011). Grounding cultural systems: Body comportment and values in Honor and Dignity cultures. European Journal of Social Psychology, 41, 456-467.

IJzerman, H., Karremans, J.C., Thomsen, L., Schubert, T.W., in press. Caring for sharing: How attachment styles modulate cues of physical warmth. Social Psychology.

IJzerman, H., \& Koole, S. (2011). From perceptual rags to metaphoric riches: Bodily, social, and cultural constraints on socio-cognitive metaphors. Psychological Bulletin, 137, 355-361.

IJzerman, H., \& Semin, G. R. (2009). The thermometer of social relations: Mapping social proximity on temperature. Psychological Science, 20, 1214-1220.

IJzerman, H., \& Semin, G. R. (2010). Temperature perceptions as a ground for social proximity. Journal of Experimental Social Psychology, 46, 867-873.
Johnson, C. (1997). Learnability in the acquisition of multiple senses: Sources reconsidered. In J. Moxley, J.Juge, \& M. Juge (Eds.), Proceedings of the Twenty-Second Annual Meeting of the Berkeley Linguistics Society (pp. 469-480). Berkeley, CA: Berkeley Press.

Johnson, S. C., Dweck, C. S., \& Chen, F. S. (2007). Evidence for infants' internal working models of attachment. Psych. Sci., 18, 501-502.

Kasahara, Y., Takayanagi, Y., Kawada, T., Itoi, K., \& Nishimori, K. (2007). Impaired thermoregulatory ability of oxytocin-deficient mice during cold-exposure. Bioscience, Biotechnology, and Biochemistry, 71, 3122-3126.

Kaschak, M. P., \& Maner, J. (2009). Embodiment, evolution, and social cognition: An integrative framework. European Journal of Social Psychology, 39, 1236-1244.

Kavanagh, D. J., Andrade, J., \& May, J. (2005). Imaginary relish and exquisite torture: The elaborated intrusion theory of desire. Psychological Review, 112, 446-467.

Kazén, M., \& Kuhl, J. (2005). Intention memory and achievement motivation: Volitional facilitation and inhibition as a function of affective contents of need-related stimuli. Journal of Personality and Social Psychology, 89, 426-448.

Kenward, M. G., \& Roger, J. H. (1997). Small sample inference for fixed effects from restricted maximum likelihood. Biometrics, 53, 983-997.

Lakoff, G., \& Johnson, M. (1999). Philosophy in the flesh: The embodied mind and its challenge to Western thought. New York: Basic Books.

Landau, M. J., Keefer, L. A., \& Meier, B. P. (2011). Wringing the perceptual rags: Reply to IJzerman and Koole 2011. Psychological Bulletin, 2, 362-365.

Landau, M. J., Meier, B. P., \& Keefer, L. A. (2010). A metaphor-enriched social cognition. Psych. Bull., 163, 1045-1067.

Mandler, J. M. (1992). How to build a baby II: Conceptual primitives. Psychological Review, 99, 587-604

Mittelmann, B., \& Wolff, H. G. (1939). Affective states and skin temperature: Experimental study of subjects with "cold hands" and Raynaud's syndrome. Psychosomatic Medicine, 1, 271-292.

Neumann, M., Scheffer, C., Cysarz, D., Bovelet, M., Tauschel, D., Taylor-Swanson, L., et al. (2011). Thermometer of warmth in the patient-provider relationships Warmomether. Patient Education and Counseling, 82, 361-369.

Over, H., \& Carpenter, M. (2009). Eighteen-month-old infants show increased helping following priming with affiliation. Psychological Science, 20, 1189-1193.

Piaget, J., \& Inhelder, B. (1969). The psychology of the child (second ed.). New York: Basic Books.

Rimm-Kaufman, S. E., \& Kagan, J. (1996). The psychological significance of change in skin temperature. Motivation and Emotion, 20, 63-78.

Santiago, J., Román, A., \& Ouellet, M. (2011). Flexible foundations of abstract thought: A review and a theory. In A. Maas, \& T. Schubert (Eds.), Spatial dimensions of social thought (pp. 47-116). Mouton: De Gruyter.

Schubert, T. W., \& Koole, S. L. (2009). The embodied self: Making a fist enhances men's power-related self-conceptions. Journal of Experimental Social Psychology, 45 828-834.

Semin, G. R., \& Fiedler, K. (1988). The cognitive functions of linguistic categories in describing persons: Social cognition and language. Journal of Personality and Social Psychology, 54, 558-568.

Semin, G. R., \& Garrido, M. V. (2012). A systemic approach to impression formation: From verbal to multimodal processes. In J. Forgas, K. Fiedler, \& C. Sedikides (Eds.), Social Thinking and Interpersonal Behavior. London: Psychology Press.

Semin, G. R., \& Smith, E. R. (2008). Embodied grounding: Social, cognitive, affective, and neuroscientific approaches. UK: Cambridge University Press.

Thomsen, L., Carey, S. (in press). Core Cognition of Relational Models, in: Banaji, M. Gelman, S. (Eds). Navigating the Social World: What infants, children, and other species teach us. Oxford University Press, New York.

Uchino, B. N., Cacioppo, J. T., \& Kiecolt-Glaser, J. K. (1996). The relationship between social support and psychological processes: A review with emphasis on underlying mechanisms and implications for health. Psychological Bulletin, 119, 488-531.

Van Beest, I., \& Williams, K. D. (2006). When inclusion costs and ostracism pays, ostracism still hurts. Journal of Personality and Social Psychology, 91, 918-928.

Veltkamp, M., Aarts, H., \& Custers, R. (2008). On the emergence of deprivationreducing behaviors: Subliminal priming of behavior representations turns deprivation into motivation. Journal of Experimental Social Psychology, 44, 866-873.

Wesselmann, E. D., Bagg, D., \& Williams, K. D. (2009). "I feel your pain": The effects of observing ostracism on the ostracism detection system. Journal of Experimental Social Psychology, 45, 1308-1311.

Wilkowski, B. M., Robinson, M. D., Meier, B. P., Carter, M. S., \& Feltman, R. (2009). “Hotheaded" is more than an expression: The embodied representation of anger in terms of heat. Emotion, 9, 464-477.

Williams, K. D. (2007). Ostracism. Annual Review of Psychology, 58, 425-452.

Williams, L. E., \& Bargh, J. A. (2008). Experiencing physical warmth promotes interpersonal warmth. Science, 322, 606-607.

Williams, K. D., Cheung, C. K. T., \& Choi, W. (2000). CyberOstracism: Effects of being ignored over the Internet. Journal of Personality and Social Psychology, 79, 748-762.

Williams, L. E., Huang, J. Y., \& Bargh, J. A. (2009). The scaffolded mind: Higher mental processes are grounded in early experience of the physical world. European Journal of Social Psychology, 39, 1257-1267.

Williams, K. D., \& Jarvis, B. (2006). Cyberball: A program for use in research on interpersonal ostracism and acceptance. Behavior Research Methods, 38, 174-180.

Wilson-Mendenhall, C. D., Barrett, L. F., Simmons, W. K., \& Barsalou, L. W. (2011). Grounding emotion in situated conceptualization. Neuropsychologia, 49, 1105-1127.

Zadro, L., Williams, K. D., \& Richardson, R. (2004). How low can you go? Ostracism by a computer is sufficient to lower self-reported levels of belonging, control, selfesteem, and meaningful existence. Journal of Experimental Social Psychology, 40, 560-567.

Zhong, C. B., \& Leonardelli, G. J. (2008). Cold and lonely: Does social exclusion literally feel cold? Psychological Science, 19, 838-842. 